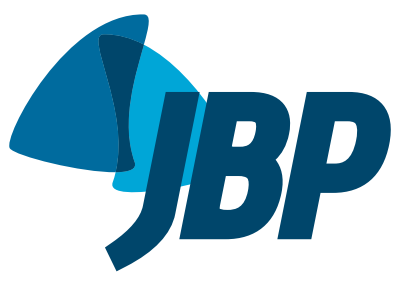

1. Programa de Pós-Graduação das Ciências Aplicadas à Saúde do Adulto, Universidade Federal de Minas Gerais UFMG - Belo Horizonte (MG) Brasil.

2. Departamento de Clínica Médica, Faculdade de Medicina, Universidade Federal de Minas Gerais - UFMG Belo Horizonte (MG) Brasil.

3. Laboratório de Função Pulmonar, Hospital das Clínicas, Universidade Federal de Minas Gerais - UFMG Belo Horizonte (MG) Brasil.

4. Centro Médico Brasil, Guarulhos (SP) Brasil.

5. Laboratório de Função Pulmonar, Hospital Cárdio Pulmonar, Salvador (BA) Brasil.

6. Departamento de Psicobiologia, Universidade Federal de São Paulo UNIFESP - São Paulo (SP) Brasil.

a. (D) http://orcid.org/0000-0002-4765-2685

b. (iD http://orcid.org/0000-0003-3891-875X

c. (D) http://orcid.org/0000-0002-0352-9589

d. (DD http://orcid.org/0000-0001-7245-4472

e. (iD http://orcid.org/0000-0002-5561-8794

f. (iD) http://orcid.org/0000-0002-6760-0663

g. (iD http://orcid.org/0000-0002-4012-4951

Submitted: 13 March 2018

Accepted: 8 June 2018.

Study carried out under the auspices of the Programa de Pós-Graduação em Ciências Aplicadas à Saúde do Adulto, Universidade Federal de Minas Gerais UFMG - Belo Horizonte (MG) Brasil.

\section{Spirometry reference values for Black adults in Brazil}

Tarciane Aline Prata ${ }^{1, a}$, Eliane Mancuzo ${ }^{2,3, b}$, Carlos Alberto de Castro Pereira ${ }^{4, c}$, Silvana Spíndola de Miranda ${ }^{2, d}$, Larissa Voss Sadigursky ${ }^{5, \mathrm{e}}$, Camila Hirotsu $^{6, \mathrm{f}}$, Sérgio Tufik ${ }^{6,9}$

\begin{abstract}
Objective: To derive reference equations for spirometry in healthy Black adult never smokers in Brazil, comparing them with those published in 2007 for White adults in the country. Methods: The examinations followed the standards recommended by the Brazilian Thoracic Association, and the spirometers employed met the technical requirements set forth in the guidelines of the American Thoracic Society/European Respiratory Society. The lower limits were defined as the 5th percentile of the residuals. Results: Reference equations and limits were derived from a sample of 120 men and 124 women, inhabitants of eight Brazilian cities, all of whom were evaluated with a flow spirometer. The predicted values for $\mathrm{FVC}_{1}, \mathrm{FEV}_{1}, \mathrm{FEV} / \mathrm{FVC}$ ratio, and PEF were better described by linear equations, whereas the flows were better described by logarithmic equations. The $\mathrm{FEV}_{1}$ and $\mathrm{FVC}$ reference values derived for Black adults were significantly lower than were those previously derived for White adults, regardless of gender. Conclusions: The fact that the predicted spirometry values derived for the population of Black adults in Brazil were lower than those previously derived for White adults in the country justifies the use of an equation specific to the former population.
\end{abstract}

Keywords: Spirometry; Reference values; African continental ancestry group.

\section{INTRODUCTION}

Spirometry plays an essential role in the diagnosis and follow-up of respiratory diseases. The values obtained by spirometry should be compared with those predicted for nonsmokers without cardiopulmonary disease. ${ }^{(1-3)}$

Reference equations for spirometry in White adults in Brazil were derived in 2007.(4) The reference values obtained by using those equations were found to differ significantly from those obtained by using other equations. ${ }^{(5-7)}$

Several studies have shown that reference spirometric values (corrected for anthropometric characteristics) are lower in Black individuals than in White individuals, and this has led to the recommendation that race-specific equations be used. $(3,7,8)$ Before spirometric reference equations were available for use in Black individuals, reference values originally derived for White individuals were used for Black individuals by applying an adjustment factor whereby the values for White individuals were reduced by $10-15 \%$; however, the adjustment was found to be inadequate. ${ }^{(9)}$

According to the 2015 Brazilian National Household Sample Survey, $45.11 \%$ of Brazilians described themselves as White (Caucasian); $45.06 \%$ described themselves as Brown (biracial); 8.86\% described themselves as Black (African); $0.47 \%$ described themselves as Yellow (Asian); and $0.38 \%$ described themselves as Red (Indigenous). ${ }^{(10)}$

In two studies conducted in Brazil, Black adults were studied in an attempt to obtain reference spirometric values, which were found to be similar to those for White adults in the country. ${ }^{(11,12)}$ All spirometry tests were performed with spirometers that are currently obsolete. $(4,13)$ Race can be determined by genetic ancestry or self-report. In a large study conducted in the USA and

Correspondence to:

Tarciane Aline Prata. Rua Piumí, 66/301, Cruzeiro, CEP 30310-080, Belo Horizonte, MG, Brasil.

Tel.: 5531 98797-5978 or 5531 2510-8859. E-mail: tarcipr@yahoo.com.br

Financial support: This study received financial support from the Brazilian Conselho Nacional de Desenvolvimento Cientifico e Tecnológico (CNPq, National

Council for Scientific and Technological Development; Grant no. 310174/2014-7). 
involving individuals who identified themselves as African American, spirometric values (corrected for age, sex, and height) were found to be lower in those with a higher percentage of African ancestry. ${ }^{(14)}$ Similarly, in a study involving a large cohort of individuals in Brazil followed from birth to age 30 years (at which time they underwent pulmonary function testing), FVC and $\mathrm{FEV}_{1}$ (corrected for height and other factors) were found to be lower in males and females with a higher percentage of African ancestry. ${ }^{(15)}$ Regardless of genetic ancestry, anthropometric characteristics (in particular, a lower ratio of trunk length to standing height in Black individuals) and environmental factors (such as nutrition and socioeconomic status) can contribute to these differences. ${ }^{(15-17)}$

The objective of the present study was to derive reference equations for spirometry in Black adults in Brazil and compare them with those published in 2007 for White adults in the country. ${ }^{(4)}$

\section{METHODS}

All data were collected under the auspices of the Respire e Viva (Breathe and Live) program in the cities of São Paulo, Rio de Janeiro, Belo Horizonte, Porto Alegre, Curitiba, Santos, Brasília, and Recife, Brazil, in 2004 and in Salvador, Belo Horizonte, and a quilombo (a community established by escaped or freed slaves) in the state of Minas Gerais, Brazil, in the 2015-2017 period. ${ }^{(4)}$ All of the participants volunteered for the study, in response to a verbal invitation or to advertisements placed in various locations. Initially, all participants completed an American Thoracic Society (ATS) Division of Lung Diseases respiratory questionnaire previously translated into Portuguese and validated for use in Brazil. ${ }^{(18,19)}$ Subsequently, they underwent testing at designated facilities. The study project was approved by the local research ethics committee (Protocol no. CAAE 60844316.0.0000.5149).

The inclusion criteria were as follows:

- being over 20 years of age (for females) or over 25 years of age (for males), ages at which peak FVC is achieved(20)

- having a body mass index (BMI) of $18-30 \mathrm{~kg} / \mathrm{m}^{2}$

- having no significant respiratory symptoms, as determined by the aforementioned questionnaire ${ }^{(19)}$

- having had no lung disease (including the flu) in the last seven days

- having no history of respiratory disease potentially resulting in permanent pulmonary dysfunction, including tuberculosis, asthma, and thoracic surgery, with asthma being defined as a lifetime history of two or more episodes of wheezing relieved by bronchodilators

- having no history of physician-diagnosed heart disease

- $\quad$ not having been diagnosed with uncontrolled hypertension
- $\quad$ not having worked (for 1 year or more) in environments in which the concentration of dust was high and therefore posed a risk of lung disease

- having never smoked

- having identified themselves as Black (African) and showing phenotypic characteristics (as determined by the investigators) such as skin color, eye color, hair color, hair texture, nose shape, and lip shape ${ }^{(21)}$

The exclusion criteria were as follows: a history of pneumonia and hospitalization in the previous year; exposure to smoke from wood-burning stoves; exposure to cigarette smoke in the bedroom; and divergence between self-reported race and individual phenotypic characteristics (as determined by the investigators).

Weight and height were measured with participants standing barefoot and wearing light clothing. Spirometry was performed with participants in a sitting position and wearing a nose clip, Multispiro spirometers (Creative Biomedics, San Clemente, CA, USA) being used in 2004 and Koko spirometers (Pulmonary Data Service Inc., Louisville, CO, USA) being used in the 2015-2017 period. All spirometers met the technical requirements set forth in the ATS guidelines. ${ }^{(2)}$ All spirometry tests were performed in accordance with the standards and acceptability and reproducibility criteria proposed by the Brazilian Thoracic Association $(B T A)^{(1)}$ and the ATS/European Respiratory Society. (22) A back-extrapolated volume of $<0.15 \mathrm{~L}$ or $5 \%$ of FVC (whichever was greater) was accepted. Peak flow was used in order to assess the initial effort. ${ }^{(1)}$ Debris, condensed water vapor, or mucus deposition on the sensor can increase the pressure gradient and result in high flows and volumes after integration (resistance error). Tests with peak flows above $14 \mathrm{~L} / \mathrm{s}$ in males and $11 \mathrm{~L} / \mathrm{s}$ in females were excluded, ${ }^{(4)}$ as were those in which peak flow was low in comparison with $\mathrm{FEV}_{1}$, indicating inadequate effort, i.e., an $\mathrm{FEV}_{1}(\mathrm{~mL}) / \mathrm{PEF}$ (L/ $\mathrm{min}$ ) ratio $>8.5$ in males and $>8.8$ in females. The aforementioned values are above the 99th percentile found in the Respire e Viva (Breath and Live) study, which was conducted in 2004 and included Black and White participants, 413 of whom were male and 447 of whom were female (unpublished data). In that study, in addition to the standard reproducibility criteria for $\mathrm{FEV}_{1}$ and FVC $(0.15 \mathrm{~L})$, at least two peak flow values lower than the highest value by $10 \%$ or less were required. ${ }^{(4)}$

After the acceptability and reproducibility criteria were met, the highest FVC, $\mathrm{FEV}_{1}$, and PEF values were recorded. Expiratory flows were derived from maneuvers with the highest sums of FVC and $\mathrm{FEV}_{1}{ }^{\cdot(1,22)}$

All tests were performed by the investigators themselves or by technicians certified by the BTA. Calibrations were performed before each session of testing with the use of $3-L$ syringes. All tests were reviewed after the three best curves had been printed.

Sample size was calculated on the basis of a recommendation from the European Respiratory Society, which suggested that studies aimed at establishing 
lung function reference values should include more than 100 males and 100 females. (23)

Statistical analysis was performed with the IBM SPSS Statistics software package, version 22.0 (IBM Corporation, Armonk, NY, USA). All calculations were performed in accordance with Pereira et al. ${ }^{(4)}$ The lower limits of the regressions were estimated by the 5th percentile of the nonstandardized residuals. The spirometric and anthropometric data obtained in São Paulo, Belo Horizonte, and Rio de Janeiro were compared by ANOVA, and the influence of location (if any) on spirometric variables was determined by analysis of covariance.

The differences between the predicted spirometry values derived for White adults in Brazil in 2007 and those derived for Black adults in the present study were plotted against the former values. The paired Student's t-test was used in order to compare the means. Given the multiple comparisons, the level of significance was set at $a<0.01$.

\section{RESULTS}

Of the 264 Black adults who underwent spirometry, 244 (124 women and 120 men) were included in the final analysis. A total of 11 women and 9 men were excluded because of discrepant FVC/height ${ }^{2}$ values or because of submaximal initial efforts. Data on the study participants were collected in the following locations: São Paulo $(n=88)$; Belo Horizonte plus a quilombo in the state of Minas Gerais $(n=83)$; Rio de Janeiro $(n=52)$; Salvador $(n=10)$; other cities in Brazil $(n=11)$. Table 1 shows anthropometric data for the study participants, by sex. Males ranged in age from 26 years to 82 years, whereas females ranged in age from 20 years to 83 years. The median height was $171 \mathrm{~cm}$ (range, 151-187 cm) in males and 158 $\mathrm{cm}$ (range, 145-175 cm) in females.

Table 2 shows spirometric data (means \pm standard deviations) for the study participants, by sex. ANOVA showed that FVC in females was lower in Belo Horizonte than in São Paulo and Rio de Janeiro. However, analysis of covariance (with age and height as covariates) showed that the difference was not significant. The mean age of females was highest in Belo Horizonte ( $56 \pm 17$ years vs. $43 \pm 14$ years; $p<0.01)$.

The predicted values for $\mathrm{FEV}_{1}, \mathrm{FVC}_{1} \mathrm{FEV}_{1} / \mathrm{FVC}$, and PEF were better described by linear equations, whereas the flows were better described by logarithmic equations. Prediction equations for males and females are shown in Table 3 and Table 4, respectively. Weight played no relevant role in any of the reference equations.

The coefficients of determination $\left(r^{2}\right)$ were generally similar between males and females, being higher for

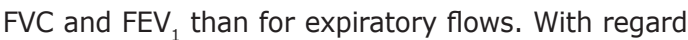
to the flows, $r^{2}$ values were highest for $\mathrm{FEF}_{75 \%}$. With regard to age, $\mathrm{FEV}_{1}$ decreased on average $24 \mathrm{~mL}$ per year in males and $17 \mathrm{~mL}$ per year in females.
The lower limit for the $\mathrm{FEV}_{1} / \mathrm{FVC}$ ratio in Black adults in Brazil was determined by subtracting 9 from the predicted value for males (Table 3) and 8 from the predicted value for females (Table 4$).(24,25)$ Values below $70 \%$ were observed among males over 60 years of age and females over 65 years of age.

Figure 1 shows a comparison of the FVC and FEV values derived for White adults in Brazil in 2007(4) with those derived for Black adults in Brazil in the present study. The predicted values for FVC and FEV were consistently lower in Black individuals than in White individuals, regardless of sex. In males, FVC was on average $0.30 \mathrm{~L}$ lower in Black individuals than in White individuals, $\mathrm{FEV}_{1}$ being $0.28 \mathrm{~L}$ lower in the former than in the latter ( $p<0.001$ for both). In females, FVC was on average $0.14 \mathrm{~L}$ lower in Black individuals than in White individuals, $\mathrm{FEV}_{1}$ being 0.11 $L$ lower in the former than in the latter $(p<0.001$ for both). The differences between the predicted values for White individuals and those for Black individuals were

Table 1. Anthropometric data (age, height, and body mass index) for the study participants, by sex.

\begin{tabular}{lcccc}
\multicolumn{1}{c}{ Variable } & \multicolumn{2}{c}{ Males } & \multicolumn{2}{c}{ Females } \\
& (n=120) & \multicolumn{2}{c}{$(\mathbf{n}=124)$} \\
Age, years & $\mathbf{n}$ & $\%$ & $\mathbf{n}$ & $\%$ \\
$20-24$ & - & - & 7 & 5.6 \\
$25-34$ & 33 & 27.5 & 31 & 25.0 \\
$35-44$ & 31 & 25.8 & 18 & 14.5 \\
$45-54$ & 23 & 19.2 & 23 & 18.5 \\
$55-64$ & 16 & 13.3 & 24 & 19.4 \\
$65-74$ & 8 & 6.7 & 13 & 10.5 \\
$\geq 75$ & 9 & 7.5 & 8 & 6.5 \\
Height, cm & & & & \\
$145-154$ & 1 & 0.8 & 29 & 23.3 \\
$155-164$ & 25 & 20.8 & 74 & 59.7 \\
$165-174$ & 55 & 45.8 & 20 & 16.1 \\
$175-184$ & 34 & 28.3 & 1 & 0.8 \\
$\geq 185$ & 5 & 4.2 & - & \\
BMI, kg/m & & & & \\
$18-24$ & 38 & 31.7 & 43 & 34.7 \\
$25-30$ & 82 & 68.3 & 81 & 65.3 \\
\hline
\end{tabular}

BMI: body mass index.

Table 2. Spirometric data for the study participants, by sex. ${ }^{\mathrm{a}}$

\begin{tabular}{lcc}
\multicolumn{1}{c}{$\begin{array}{c}\text { Variable } \\
\text { (n }=120)\end{array}$} & $\begin{array}{c}\text { Memales } \\
\text { (n= 124) }\end{array}$ \\
\hline $\mathrm{FVC}, \mathrm{L}$ & $4.42 \pm 0.78$ & $3.10 \pm 0.52$ \\
$\mathrm{FEV}_{1}, \mathrm{~L}$ & $3.55 \pm 0.69$ & $2.55 \pm 0.48$ \\
$\mathrm{FEV}_{1} / \mathrm{FVC}, \%$ & $80.3 \pm 5.4$ & $82.0 \pm 5.4$ \\
$\mathrm{FEF}_{25-75 \%}, \mathrm{~L} / \mathrm{s}^{\mathrm{b}}$ & $3.54 \pm 1.17$ & $2.77 \pm 0.93$ \\
$\mathrm{FEF}_{50 \%}, \mathrm{~L} / \mathrm{s}^{\mathrm{b}}$ & $4.39 \pm 1.36$ & $3.54 \pm 1.06$ \\
$\mathrm{FEF}_{75 \%}, \mathrm{~L} / \mathrm{s}^{\mathrm{b}}$ & $1.43 \pm 0.63$ & $1.11 \pm 0.52$ \\
$\mathrm{PEF}, \mathrm{L} / \mathrm{s}$ & $9.77 \pm 2.07$ & $6.73 \pm 1.28$ \\
\hline
\end{tabular}

aalues expressed as mean \pm SD, except where otherwise indicated. 'balues expressed as mean \pm logarithmic SD. 
found to increase as the predicted values increased. A significant positive correlation was found between height and FVC in males and females $(r=0.93$ and $r$ $=8.88$, respectively; $\mathrm{p}<0.001$ for both).
The paired Student's t-test showed that the $\mathrm{FEV}_{1} / \mathrm{FVC}$ ratio was higher in White males than in Black males, albeit only $1.0 \%$ higher on average $(p=0.021)$. In females, the $\mathrm{FEV}_{1} / \mathrm{FVC}$ ratio was similar between White

Table 3. Regression equations, coefficient of determination $\left(r^{2}\right)$, and lower limits for spirometric variables in Black males.

$\begin{array}{llllll}\text { Type of equation Height coefficient } & \text { Age coefficient } & \text { Constant } & r^{2} & \text { Lower limit }\end{array}$

Linear

FVC, I

$\mathrm{FEV}_{1}, \mathrm{l}$

0.048

$\mathrm{FEV}_{1} / \mathrm{FVC}, \%$

0.033

PEF, L/S

$-0.134$

0.059

Logarithmic

$\mathrm{FEF}_{25-75 \%}$, L/S

$\mathrm{FEF}_{50 \%}, \mathrm{~L} / \mathrm{S}$

$\mathrm{FEF}_{75 \%}$, L/s
$-2.931$

$-0.989$

112.0

1.903

3.735

3.383

3.872

$-0.670$

$-0.517$

$\begin{array}{ll}0.52 & P-0.78 \\ 0.57 & P-0.76 \\ 0.26 & P-8.70 \\ 0.24 & P-2.67\end{array}$

P: predicted. Linear equations: height $\times$ coefficient - age $\times$ coefficient \pm constant. Example: $F V C=$ height $\times 0.048$ - age $\times 0.019-2.931$ Logarithmic equations: natural log (log height $\times$ coefficient $-\log$ age $\times$ coefficient \pm constant). Example: $\mathrm{FEF}_{25-75 \%}$ $=2.7183^{(-\log n \text { age } \times 0.670+3.735)}$.

Table 4. Regression equations, coefficient of determination $\left(r^{2}\right)$, and lower limits for spirometric variables in Black females.

\begin{tabular}{|c|c|c|c|c|c|}
\hline Type of equation & Height coefficient & Age coefficient & Constant & $r^{2}$ & Lower limit \\
\hline \multicolumn{6}{|l|}{ Linear } \\
\hline FVC, L & 0.035 & -0.013 & -1.83 & 0.47 & $P-0.66$ \\
\hline $\mathrm{FEV}_{1}, \mathrm{~L}$ & 0.025 & -0.017 & -0.69 & 0.56 & $P-0.55$ \\
\hline $\mathrm{FEV}_{1} / \mathrm{FVC}, \%$ & -0.074 & -0.200 & 103.2 & 0.33 & $P-7.8$ \\
\hline $\mathrm{PEF}, \mathrm{L} / \mathrm{s}$ & - & -0.029 & 8.134 & 0.14 & P- 1.77 \\
\hline \multicolumn{6}{|l|}{ Logarithmic } \\
\hline $\mathrm{FEF}_{25-75 \%}, \mathrm{~L} / \mathrm{s}$ & - & -0.625 & 3.32 & 0.37 & $P \times 0.63$ \\
\hline $\mathrm{FEF}_{50 \%}, \mathrm{~L} / \mathrm{s}$ & - & -0.436 & 2.862 & 0.23 & $P \times 0.61$ \\
\hline $\mathrm{FEF}_{75 \%}, \mathrm{~L} / \mathrm{s}$ & - & -1.01 & 3.805 & 0.50 & $P \times 0.54$ \\
\hline
\end{tabular}

P: predicted. Linear equations: height $\times$ coefficient - age $\times$ coefficient \pm constant. Logarithmic equations: natural log (log height $x$ coefficient $-\log$ age $x$ coefficient \pm constant).
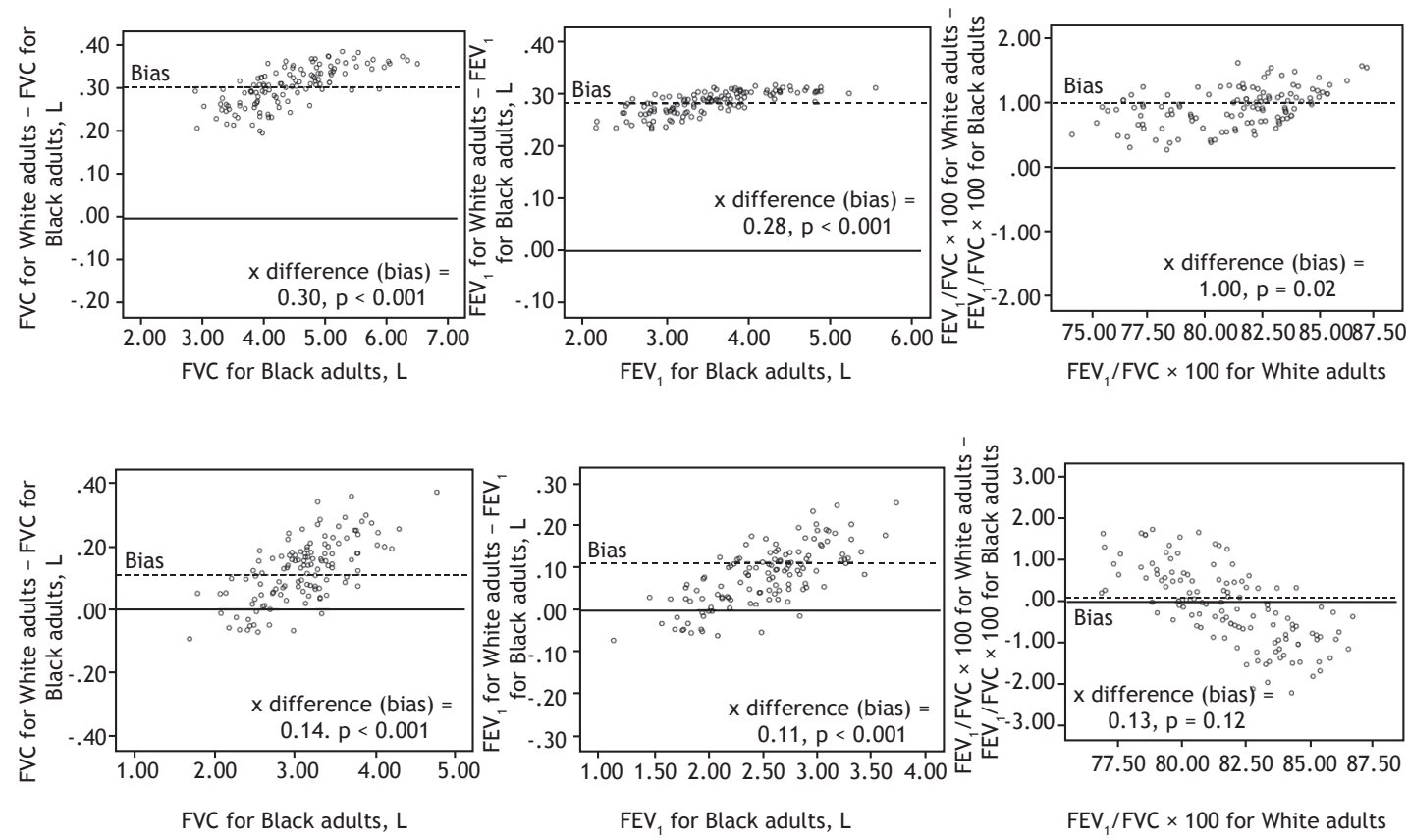

Figure 1. Differences between the FVC, $\mathrm{FEV}_{1}$, and $\mathrm{FEV}_{1} / \mathrm{FVC} \%$ values predicted for White adults by Pereira et al.(4) and those predicted for Black males (above) and females (below). 
individuals and Black individuals $(p=0.12)$. There was no significant correlation between the difference in $\mathrm{FEV}_{1} / \mathrm{FVC}$ between White and Black individuals and age in males or females.

When the predicted values for White and Black individuals were plotted, the percentage difference was found to be proportional for FVC and FEV $(\sim 6.5 \%$; $p$ $<0.01$ ) in males but not in females (Figure 2 ).

\section{DISCUSSION}

To our knowledge, the present study is the first multicenter study in Brazil to derive reference equations for spirometry in Black adults by including a representative sample of volunteers and using spirometers meeting the ATS criteria. (2) A comparison between the equations derived for Black adults in the present study and those derived for White adults in $2007^{(4)}$ showed a disproportionate difference between the two regarding FVC and $\mathrm{FEV}_{1}$ in females, indicating the need for an equation specific to the former population and the inappropriateness of applying a correction factor to values originally derived for White individuals. ${ }^{(9)}$ Although the differences between the two groups of equations regarding FVC and $\mathrm{FEV}_{1}$ in males were proportional, they were lower than reported in the literature. ${ }^{(9)}$
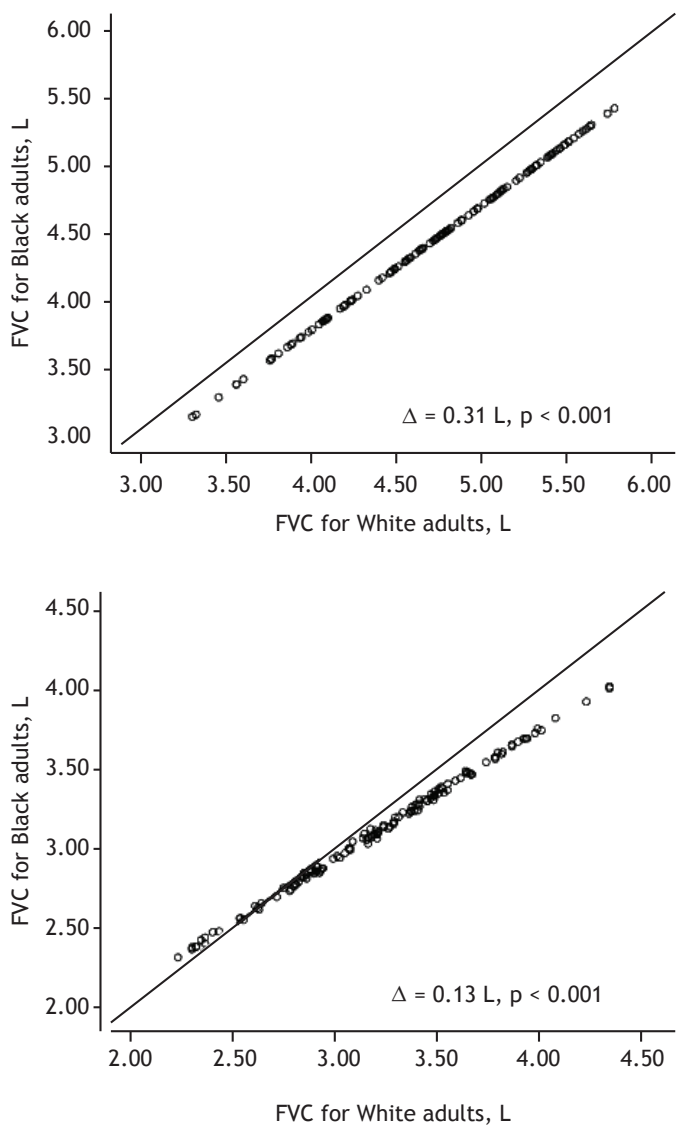

Studies aimed at deriving lung function reference values should include only nonsmokers without respiratory symptoms or cardiopulmonary disease. To that end, a previously validated respiratory epidemiology questionnaire should be used. If all of the aforementioned criteria are met, it is valid to use volunteers to establish reference values. $(18,26,27)$

Reference values should not be extrapolated to age groups or patient heights other than those included in the regression equations. ${ }^{(1)}$ Our study sample was representative of Black adults in Brazil because males and females of varying heights and ages were included in the study. The oldest males and females meeting the criteria for inclusion in the present study were 82 years old and 83 years old, respectively.

The number of participants over 65 years of age was low in the present study because it is difficult to find healthy 65-year-old individuals meeting the inclusion criteria. ${ }^{(4)}$ With regard to participant height, there was no difference between the present study and the study published in 2007.(4) The median height of the individuals who participated in the present study was found to be similar to that of those in the Brazilian population: $170.5 \mathrm{~cm}$ vs. $171 \mathrm{~cm}$ in males and 158 $\mathrm{cm}$ vs. $159 \mathrm{~cm}$ in females. (28) The negative correlation between the $\mathrm{FEV}_{1} / \mathrm{FVC}$ ratio and height in the present study was due to increased expiratory muscle strength
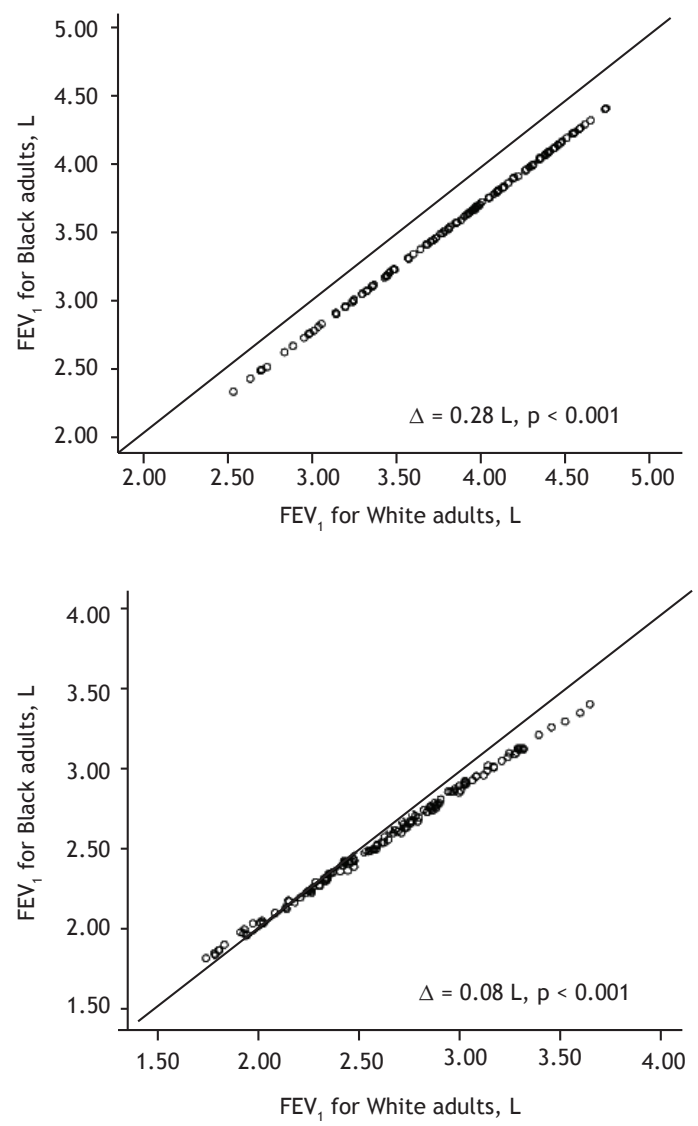

Figure 2. Comparisons between the FVC and $\mathrm{FEV}_{1}$ values predicted for White adults by Pereira et al. ${ }^{(4)}$ and those predicted for Black males (above) and females (below). 
and, consequently, airway compression. (1) Individuals with a BMI > $30 \mathrm{~kg} / \mathrm{m}^{2}$ were not included, the effect of obesity on lung volumes therefore being excluded. (29)

The process of building a regression model involves several steps, and, because of their simplicity, linear equations should be preferred whenever the adjustment is similar to other models. As occurred in the study in which reference equations were derived for White adults in Brazil, (4) the flow equations derived in the present study followed a logarithmic curve, the lower limit therefore being a fixed percentage of the predicted value, with sensitivity for detecting airflow obstruction. (4) In the present study, $\mathrm{FEF}_{75 \%}$ was found to have the highest coefficient of determination with anthropometric data, a finding that is of particular interest and is consistent with those of the aforementioned study. ${ }^{(4)}$

Approximately $10 \%$ of the White individuals included in the aforementioned study ${ }^{(4)}$ were obese; nevertheless, FVC and $\mathrm{FEV}_{1}$ were lower in the present study than in that study. ${ }^{(4)}$

It has long been recognized that lung function values are lower in Black adults than in White adults, although the $\mathrm{FEV}_{1} / \mathrm{FVC}$ ratio is similar. ${ }^{(7,8,16,30-32)}$ These findings have been confirmed in studies employing genetic ancestry to determine race. ${ }^{(14,15)}$

Studies conducted in Brazil and establishing a relationship between self-reported skin color and genetic ancestry have shown conflicting results. In a study conducted by Menezes et al., ${ }^{(15)}$ a good correlation was found between self-reported skin color and genetic ancestry. Similar results were obtained in an unpublished study involving 137 individuals recruited in São Paulo. However, in another study conducted in Brazil, no correlation was found between self-reported race and genetic ancestry. ${ }^{(33)}$ In individual cases, the apparent race and genetically determined race can be widely divergent. In addition, genetic ancestry testing is not without limitations. ${ }^{(34)}$

The difference in lung function across races has been attributed in part to anthropometric factors, including a lower ratio of trunk length to standing height (Cormic index) in Black individuals. ${ }^{(15,16,32,35)}$ The aforementioned ratio decreases as height increases, thus explaining why the difference in lung function between Black and White individuals increases as height increases. ${ }^{(36)}$ Other explanations include socioeconomic and environmental factors, which are closely related to race in several countries, including Brazil. ${ }^{(35,37)}$ However, in a study conducted in the USA and in the study by Menezes et al., ${ }^{(5,15)}$ socioeconomic and environmental factors were found to have only a minor influence on lung function. Anthropometric factors, socioeconomic conditions, and other indicators explain in part the difference in spirometric values across races. ${ }^{(17)}$ Lung function is determined by several genes, and extensive genetic mapping combined with determination of race (ancestry) might refine predicted lung function values beyond anthropometric measures. ${ }^{(38)}$

Unlike our study, two studies involving Black adults in Brazil found no differences between the predicted spirometry values derived for Black adults and those derived for White adults. ${ }^{(11,12)}$ Scalambrini et al. ${ }^{(11)}$ studied 139 Black men and 56 Black women and compared the obtained values with those obtained in a parallel study involving White individuals (334 men and 141 women), (37) both studies having been conducted in the 1990s and having employed a Vitalograph spirometer (Vitalograph, Buckingham, UK). Race was determined by the investigators. In an unpublished review of the data from the two aforementioned studies, ${ }^{(11,37)}$ FVC was found to be significantly lower in Black males and females.

Rufino et al. ${ }^{(12)}$ derived predicted values from a sample of 146 male volunteers and 242 female volunteers in the state of Rio de Janeiro, Brazil. Race was self-reported. Although there were no apparent differences between Black and White individuals regarding FVC or FEV ${ }_{1}$, the data were raw and not corrected for age or height. The fact that a single bellows spirometer (Vitalograph) was used during the 4-year study period explains why FVC values were on average $0.5 \mathrm{~L}$ lower than those found by Pereira et al.(4) Because of accumulation of debris and humidity (and because cleaning is impossible), the compliance of the spirometer bellows decreases with repeated use, and this can lead to an underestimation of the parameter values. ${ }^{(4,13)}$

The present study has some limitations that should be noted. Sitting height and socioeconomic status were not assessed. Had they been assessed, the differences in FVC and $\mathrm{FEV}_{1}$ between Black and White individuals might have been less dramatic. ${ }^{(16)}$ The number of individuals over 80 years of age was small. Women taller than $175 \mathrm{~cm}$ were not represented.

In conclusion, the predicted spirometry values obtained in the present study were derived from a large sample of Black adults in Brazil. The fact that the predicted spirometry values derived for the population of Black adults in Brazil were lower than those previously derived for White adults in the country(4) justifies the use of equations specific to the former population.

\section{REFERENCES}

1. Sociedade Brasileira de Pneumologia e Tisiologia. Diretrizes para Testes de Função Pulmonar. J Pneumol. 2002;28(Suppl 3):S1-S238.

2. Lung function testing: selection of reference values and interpretative strategies. American Thoracic Society. Am Rev Respir Dis. 1991;144(5):1202-18. https://doi.org/10.1164/ajrccm/144.5.1202

3. Pellegrino R, Viegi G, Brusasco V, Crapo RO, Burgos F, Casaburi R, et al. Interpretative strategies for lung function tests. Eur Respir J. 2005;26(5):948-68. https://doi.org/10.1183/09031936.05.00035205

4. Pereira CA, Sato T, Rodrigues SC. New reference values for forced spirometry in white adults in Brazil. J Bras Pneumol. 2007;33(4):397- 


\section{6. https://doi.org/10.1590/S1806-37132007000400008}

5. Duarte AA, Pereira CA, Rodrigues SC. Validation of new brazilian predicted values for forced spirometry in caucasians and comparison with predicted values obtained using other reference equations. Bras Pneumol. 2007;33(5):527-35. https://doi.org/10.1590/S180637132007000500007

6. Pereira CA, Duarte AA, Gimenez A, Soares MR. Comparison between reference values for FVC, FEV1, and FEV1/FVC ratio in White adults in Brazil and those suggested by the Global Lung Function Initiative 2012. J Bras Pneumol. 2014;40(4):397-402. https://doi.org/10.1590/ S1806-37132014000400007

7. Hankinson JL, Odencrantz JR, Fedan KB. Spirometric reference values from a sample of the general U.S. population. Am J Respir Crit Care Med. 1999;159(1):179-87. https://doi.org/10.1164/ ajrccm.159.1.9712108

8. Quanjer PH, Stanojevic S, Cole TJ, Baur X, Hall GL, Culver BH, et al. Multi-ethnic reference values for spirometry for the 3-95-yr age range: the global lung function 2012 equations. Eur Respir J. 2012;40(6):1324-43. https://doi.org/10.1183/09031936.00080312

9. Scanlon PD, Shriver MD. "Race correction" in pulmonary-function testing. N Engl J Med. 2010;363(4):385-6. https://doi.org/10.1056/ NEJMe1005902

10. Instituto Brasileiro de Geografia e Estatística [homepage on the Internet]. Rio de Janeiro: IBGE; [cited 2017 Sep 16]. Pesquisa das Características Étnico-Raciais da População - PCERP. Available from: https://www.ibge.gov.br/estatisticas-novoportal/sociais/ populacao/9372-caracteristicas-etnico-raciais-da-populacao. html? =\&t=0-que $-e$

11. Scalambrini Costa F, Scueiri CEB, Silva Jr JW, Pereira CAC, Nakatani J. Valores de referência para espirometria em uma amostra da população brasileira adulta da raça negra. J Pneumol. 1996;22:16570

12. Rufino R, Costa CH, Lopes AJ, Maiworm Al, Maynard K, Silva LM, et al. Spirometry reference values in the Brazilian population. Braz J Med Biol Res. 2017:50(3):e5700. https://doi.org/10.1590/1414$431 \times 20175700$

13. Louw SJ, Goldin JG, Joubert G. Spirometry of healthy adult South African men. Part I. Normative values. S Afr Med J. 1996;86(7):814-9.

14. Kumar R, Seibold MA, Aldrich MC, Williams LK, Reiner AP, Colangelo $\mathrm{L}$, et al. Genetic ancestry in lung-function predictions. N Engl J Med. 2010;363(4):321-30. https://doi.org/10.1056/NEJMoa0907897

15. Menezes AM, Wehrmeister FC, Hartwig FP, Perez-Padilla R, Gigante DP, Barros FC, et al. African ancestry, lung function and the effect of genetics. Eur Respir J. 2015;45(6):1582-9. https://doi. org/10.1183/09031936.00112114

16. Harik-Khan RI, Fleg JL, Muller DC, Wise RA. The effect of anthropometric and socioeconomic factors on the racial difference in lung function. Am J Respir Crit Care Med. 2001;164(9):1647-54. https://doi.org/10.1164/ajrccm.164.9.2106075

17. Braun L, Wolfgang M, Dickersin K. Defining race/ethnicity and explaining difference in research studies on lung function. Eur Respir J. 2013;41(6):1362-70. https://doi.org/10.1183/09031936.00091612

18. Ferris BG. Epidemiology Standardization Project (American Thoracic Society). Am Rev Respir Dis. 1978;118(6 Pt 2):1-120.

19. Aguiar VA, Beppu OS, Romaldini H, Ratto OR, Nakatani J. Validade de um questionário respiratório modificado (ATS-DLD-78) como instrumento de um estudo epidemiológico em nosso meio. J Pneumol. 1988;14(3):111-6.

20. Burrows B, Cline MG, Knudson RJ, Taunig LM, Lebowitz MD. A descriptive analysis of the growth and decline of the FVC and FEV1. Chest. 1983:83(5):717-24. https://doi.org/10.1378/chest.83.5.717

21. Parra FC, Amado RC, Lambertucci JR, Rocha J, Antunes CM, Pena SD. Color and genomic ancestry in Brazilians. Proc Natl Acad Sci U S A. 2003;100(1):177-82. https://doi.org/10.1073/pnas.0126614100
22. Miller MR, Hankinson J, Brusasco V, Burgos F, Casaburi R, Coates A et al. Standardisation of spirometry. Eur Respir J. 2005;26(2):319-38. https://doi.org/10.1183/09031936.05.00034805

23. Stocks J, Quanjer PH. Reference values for residual volume functional residual capacity and total lung capacity. ATS Workshop on Lung Volume Measurements. Official Statement of The European Respiratory Society. Eur Respir J. 1995;8(3):492-506. https://doi.org/ 10.1183/09031936.95.08030492

24. Miller A, Thornton JC. The interpretation of spirometric measurements in epidemiologic surveys. Environ Res. 1980;23(2):444-68

25. Miller MR, Pincock AC. Predicted values: how should we use them? Thorax. 1988;43(4):265-7.

26. Marsh $S$, Aldington $S$, Williams $M$, Weatherall $M$, Shirtcliffe $P$ McNaughton $A$, et al. Complete reference ranges for pulmonary function tests from a single New Zealand population. N Z Med J. 2006;119(1244):U2281

27. Gräsbeck R. The evolution of the reference value concept. Clin Chem Lab Med. 2004;42(7):692-7. https://doi.org/10.1515/CCLM.2004.118

28. Instituto Brasileiro de Geografia e Estatística (IBGE). Sistema IBGE de Recuperação Automática [homepage on the Internet]. Rio de Janeiro: IBGE; [cited 2017 Sep 16]. Tabela 2645-Estimativas populacionais das medianas de altura e peso das crianças, adolescentes e adultos por sexo, situação do domicílio e idade-Brasil e Grande Regiões. Available from: https://sidra.ibge.gov.br/tabela/2645

29. Melo LC, Silva MA, Calles AC. Obesity and lung function: systematic review. Einstein (Sao Paulo). 2014;12(1):120-5. https:// doi.org/10.1590/S1679-45082014RW2691

30. Burney PG, Hooper RL. The use of ethnically specific norms for ventilatory function in African-American and white populations. Int J Epidemiol. 2012;41(3):782-90. https://doi.org/10.1093/ije/dys011

31. Glindmeyer HW, Lefante JJ, McColloster C, Jones RN, Weill $\mathrm{H}$. Blue-collar normative spirometric values for Caucasian and African-American men and women aged 18 to 65 . Am J Respir Crit Care Med. 1995;151(2 Pt 1):412-22. https://doi.org/10.1164/ ajrccm.151.2.7842200

32. Hsu KH, Jenkins DE, Hsi BP, Bourhofer E, Thompson V, Tanakawa $\mathrm{N}$, et al. Ventilatory functions of normal children and young adults-Mexican-American, white, and black. I. Spirometry. J Pediatr. 1979;95(1):14-23. https://doi.org/10.1016/S0022-3476(79)80075-X

33. Pimenta JR, Zuccherato LW, Debes AA, Maselli L, Soares RP, Moura-Neto RS, et al. Color and genomic ancestry in Brazilians: a study with forensic microsatellites. Hum Hered. 2006;62(4):190-5. https://doi.org/10.1159/000096872

34. Bolnick DA, Fullwiley D, Duster T, Cooper RS, Fujimura JH, Kahn $J$, et al. Genetics. The science and business of genetic ancestry testing. Science. 2007;318(5849):399-400. https://doi.org/10.1126/ science.1150098

35. Goldin JG, Louw SJ, Joubert G. Spirometry of healthy adult South African men. Part II. Interrelationship between socio-environmental factors and 'race' as determinants of spirometry. S Afr Med J. 1996;86(7):820-6.

36. Bardeen CR. General relations of sitting height to stature and of sitting height and stature to weight. Am J Phys Anthropol. 1923;6(4):35588. https://doi.org/10.1002/ajpa.1330060403

37. Instituto Brasileiro de Geografia e Estatística (IBGE) [homepage on the Internet]. Rio de Janeiro: IBGE; [cited 2017 Sep 16]. Síntese de indicadores sociais: uma análise das condições de vida da população brasileira 2016. [Adobe Acrobat document, 141p.]. Available from: https://biblioteca.ibge.gov.br/visualizacao/livros/liv98965.pdf

38. Ortega VE, Kumar R. The Effect of Ancestry and Genetic Variation on Lung Function Predictions: What Is "Normal" Lung Function in Diverse Human Populations? Curr Allergy Asthma Rep 2015;15(4):16. https://doi.org/10.1007/s11882-015-0516-2 